\title{
INFLUÊNCIA DA COMPOSIÇÃO CORPORAL REGIONAL E TOTAL SOBRE O DESEMPENHO DE NADO E ÍNDICES AERÓBIOS
}

\author{
INFLUENCE OF REGIONAL AND WHOLE-BODY COMPOSITION ON SWIMMING PERFORMANCE \\ AND AEROBIC INDICES
}

Artigo Original

Original ARTICLE

Artículo Original

\author{
INFLUENCIA DE LA COMPOSICIÓN CORPORAL REGIONAL Y TOTAL EN EL RENDIMIENTO \\ DE NADO Y ÍNDICES AEROBIOS
}

\begin{abstract}
Dalton Müller Pessôa Filho1,2
(Educador Físico)

Astor Reis Simionato ${ }^{2}$

(Educador Físico)

Leandro Oliveira da Cruz Siqueira ${ }^{2}$ (Educador Físico)

Mário André Espada ${ }^{3}$

(Educador Físico)

Daniel Pestana ${ }^{4}$ (Educador Físico)

1. Universidade Estadual

Paulista Júlio de Mesquita Filho

(UNESP), Faculdade de Ciências,

Departamento de Educação Física,

Bauru, SP, Brasil.

2. Universidade Estadual Paulista Júlio de Mesquita Filho (UNESP),

Instituto de Biociências, Rio Claro,

SP, Brasil.

3. Instituto Politécnico Setúbal,

Portugal.

4. Associação Bauruense de

Desportes Aquático (ABDA),

Bauru SP, Brasil.
\end{abstract}

\section{Correspondência:}

Departamento de Educação

Física, Faculdade de Ciências,

Universidade Estadual Paulista Júlio de Mesquita Filho (UNESP), Bauru,

São Paulo, Brasil.

Av. Eng. Luiz Edmundo Carrijo

Coube, 14-01. Vargem Limpa,

Bauru, SP, Brasil. 17033-360.

dmpf@fc.unesp.br

\section{RESUMO}

Introdução: Poucos estudos analisaram a contribuição da composição regional de nadadores para o perfil aeróbio, anaeróbio e o desempenho de nado. Objetivo: Verificar a influência da composição corporal regional e total sobre índices da aptidão aeróbia e anaeróbia em nado atado e livre, bem como sobre o desempenho de curta e média duração. Métodos: Onze nadadores (18,0 \pm 4,0 anos) foram submetidos a: (1) teste incremental em nado atado, com coleta de gases respiração-a-respiração ( $K 4 b^{2}$ associado ao novo-AquaTrainer $\left.{ }^{\circledR}\right)$; e (2) tempo limite nos desempenhos de 200, 400 e 800 metros de nado livre. A regressão linear entre distância e tempo $\left(d-t_{\text {Lim }}\right)$ empregou o método dos quadrados mínimos. O coeficiente de Pearson (r) averiguou as correlações da composição corporal regional e total com índices da aptidão aeróbica e anaeróbica em nado atado e livre. Resultados: Os valores da massa isenta de gordura (MIG) foram: 61,7 $\pm 7,4 \mathrm{~kg} ; 7,5 \pm 1,1 \mathrm{~kg} ; 28,3 \pm 3,7 \mathrm{~kg} ; 22,1 \pm 2,5 \mathrm{~kg}$, respectivamente para corpo todo, membros superiores (MS), tronco (T) e membros inferiores (MI). O consumo máximo de oxigênio $\left(\mathrm{VO}_{2 \text { max }}\right)$ foi $52,1 \pm 5,3 \mathrm{ml} \times \mathrm{kg}^{-1} \times \mathrm{min}^{-1}$, sendo a carga correspondente $\left(\mathrm{iVO}_{2 \text { max }}\right)$ de 93,9 $\pm 12,2$ N. O tempo em $200(132,2 \pm 9,7 \mathrm{~s}), 400(296,8 \pm 17,2 \mathrm{~s})$ e 800 metros $(619,5 \pm 26,9 \mathrm{~s})$ forneceu velocidade crítica

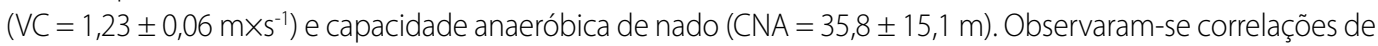
$\mathrm{iVO}_{2 \text { max }}$ CAN e $v_{200 m}$ com MIG para MS $(r=0,64 ; 0,67$ e 0,76), porém a MIG para T, MI e corporal demonstraram correlações apenas com $v_{200 m}(r=0,75 ; 0,69$ e 0,75) e CAN $(r=0,71 ; 0,69$ e 0,75). Conclusão: Houve, portanto, influência da MIG regional e corporal sobre o desempenho de curta distância e reservas anaeróbias, sendo a MIG-MS também influente sobre a $\mathrm{iVO}_{2 \max }$ e assim relacionada ao aprimoramento do desempenho de nado.

Descritores: aptidão física; absorciometria de fóton; desempenho atlético; natação.

\section{ABSTRACT}

Introduction: There have been few studies analyzing the regional body contribution of swimmers for aerobic and anaerobic profiles and swimming performance. Objective: To verify the influence of regional and whole-body composition on aerobic and anaerobic fitness indices in free and tethered swimming, as well as short-and mediumterm performance. Methods: Eleven swimmers (18.0 \pm 4.0 years old) were submitted to: (1) an incremental test in tethered swimming, with breath-by-breath gas exchange sampling ( $K 4 b^{2}$ associated with the new-AquaTrainer $\left.{ }^{\circledR}\right)$, and (2) timeout while performing the 200, 400 and 800 meter freestyle. Linear regression analysis between distance and time ( $\left.d-t_{\text {Lim }}\right)$ was performed using the least squares method. Pearson's coefficient ( $r$ ) was used to test the correlations between regional and whole-body composition and aerobic and anaerobic fitness indices in freestyle and tethered swimming. Results: Mean values for fat free mass (FFM) were: $61.7 \pm 7.4 \mathrm{~kg} ; 7.5 \pm 1.1 \mathrm{~kg} ; 28.3 \pm 3.7 \mathrm{~kg} ; 22.1 \pm 2.5$ $\mathrm{kg}$, respectively, for the whole-body, upper-limbs (UL), trunk (T) and lower-limbs (LL). Maximal oxygen uptake $\left(V_{2 \max }\right)$ was $52.1 \pm 5.3 \mathrm{~m} \times \mathrm{kgg}^{-1} \times \mathrm{min}^{-1}$, and respective load $\left(\mathrm{VO}_{2 \max }\right)$ was $93.9 \pm 12.2 \mathrm{~N}$. The timeout in $200(132.2 \pm 9.7 \mathrm{~s}), 400$ (296.8 $\pm 17.2 \mathrm{~s})$ and 800 meters $(619.5 \pm 26.9 \mathrm{~s})$ provided critical velocity $\left(C V=1.23 \pm 0.06 \mathrm{~m} \times \mathrm{s}^{-1}\right)$ and anaerobic swimming capacity ( $A S C=35.8 \pm 15.1 \mathrm{~m}$ ). Correlations were observed for $\mathrm{IVO}_{2 \max }$ ASC and $v_{200 \mathrm{~m}}$ with FFM for UL $(r=0.64$; 0.67 and 0.76$)$, but FFM for T, LL and whole body were related only with $v_{200 m}(r=0.75 ; 0.69$ and 0.75$)$ and ASC $(r=$ $0.71 ; 0.69$ and 0.75$)$. Conclusion: Regional and whole-body FFM influenced short-term performance and anaerobic reserves; FFM for UL was also related to $\mathrm{IVO}_{2 \max }$ and was therefore associated with improved swimming performance.

Keywords: Physical fitness, Absorptiometry, photon; Athletic performance; Swimming.

\section{RESUMEN}

Introducción: Pocos estudios han examinado la contribución de la composición regional de los nadadores para el perfil aerobio, anaerobio y el rendimiento de nado. Objetivo: Verificar la influencia de la composición corporal regional y total sobre indices de aptitud aerobia y anaerobia en nado estacionario y libre, así como sobre el rendimiento de corta y media duración. Métodos: Once nadadores (18,0 $\pm 4,0$ años) fueron sometidos a: (1) test incremental en nado estacionario, con coleta de gases respiración a respiración ( $K 4 b^{2}$ asociado al nuevo-AquaTrainer $\left.{ }^{\circledR}\right)$; y (2) tiempo límite en el rendimiento de 200, 400 y 800 metros en nado libre. La regresión lineal entre la distancia y el tiempo ( $d$ - $\left.t_{\text {Lim }}\right)$ utilizó el método de los mínimos cuadrados. Se empleó el coeficiente de Pearson ( $r$ ) para examinar 
las correlaciones entre la composición corporal regional y total con los índices de capacidad aerobia y anaerobia

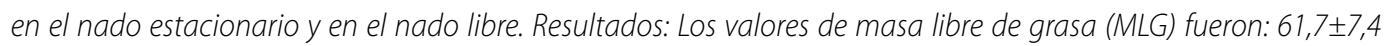
$\mathrm{kg} ; 7,5 \pm 1,1 \mathrm{~kg} ; 28,3 \pm 3,7 \mathrm{~kg} ; 22,1 \pm 2,5 \mathrm{~kg}$, respectivamente, para todo el cuerpo, extremidades superiores (ES), tronco (T) y extremidades inferiores (El). El consumo máximo de oxígeno $\left(V_{2 \text { máx }}\right)$ fue $52,1 \pm 5,3 \mathrm{ml} \times \mathrm{kg}^{-1} \times \mathrm{min}^{-1}$, y la carga correspondiente ( $\mathrm{iVO}_{2 \text { máx }}$ ) fue 93,9 \pm 12,2 N. El tiempo en 200 (132,2 $\left.\pm 9,7 \mathrm{~s}\right), 400(296,8 \pm 17,2 \mathrm{~s})$ y 800 metros $(619,5$ $\pm 26,9 \mathrm{~s}$ ) estableció la velocidad crítica $\left(V C=1,23 \pm 0,06 \mathrm{~m} \times \mathrm{s}^{-1}\right)$ y la capacidad del nado anaerobia (CNA $=35,8 \pm$ $15,1 \mathrm{~m})$. Se verificaron correlaciones entre $i V \mathrm{~V}_{2 \text { máx }}$ CNA y $v_{200 m}$ con $M L G$ de $E S(r=0,64,0,67$ y 0,76), pero la $M L G$ para T, El y corporal demostraron correlaciones sólo con la $v_{200 m}(r=0,75,0,69$ y 0,75) y la CNA $(r=0,71,0,69$ y 0,75). Conclusión: Por lo tanto, hubo influencia de la MLG regional y total en el rendimiento a corto plazo y en las reservas anaerobias, mientras la MLG-ES influye en la iVO ${ }_{2 m a ́ x}$ y así en la mejora del rendimiento en la natación.

Descriptores: Aptitud física; Absorciometría de fotón; Rendimiento atlético; Natación.

\section{INTRODUÇÃO}

O nado-atado tem sido reportado como um ergômetro amplamente usado para mensurar a força da braçada realizada durante os tipos de nado ${ }^{1,2}$, uma vez que este contexto é uma condição específica para simular as características da natação, com respeito ao ambiente?, resposta neuromuscular ${ }^{2,3}$, resposta fisiológica ${ }^{4}$ e influência dos parâmetros antropométricos e morfológicos do corpo (tamanho, formato, estatura e peso corporal) sobre as forças de propulsão e de arrasto ${ }^{5}$.

Além disto, alguns resultados mostram que o nado-atado pode ser uma boa ferramenta na avaliação da aptidão aeróbia de nadadores, uma vez que a força crítica (inclinação do modelo força-tempo limite) em nado-atado apresenta boas correlações com outros parâmetros da avaliação aeróbia de nadadores, como o limiar de lactato (LL) e a velocidade de nado nos 400 metros $\left(v_{400 m}\right)$, assim como com a velocidade média no teste de 30 minutos $(\mathrm{T} 30)^{4}$. Ainda, valores de $\mathrm{VO}_{2 \max }$ obtidos em nado-

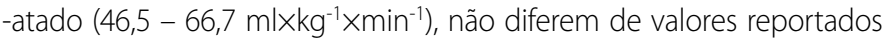
em nado-livre ${ }^{6}$, porém são maiores que valores reportados em testes inespecíficos, como em ergômetros de braço ou perna e em esteira ${ }^{7}$. Assim, o nado-atado, sem deslocamento, contextualiza-se como meio ecológico para simular o nado-livre (condição não-atada) em seus diferentes tipos de técnica ${ }^{8}$, bem como fornecer informações confidentes sobre a capacidade muscular metabólica e tensional durante a braçada ${ }^{2-9}$.

Por sua vez, em nado-livre, o modelo distância-tempo ( $d$ - $\left.t_{\text {Lim }}\right)$, que fornece a velocidade crítica (VC) e a distância de nado suprida pelas reservas anaeróbias (CNA, ou capacidade de nado anaeróbia, que é similar ao parâmetro $W^{\prime}$ do modelo potência-tempo limite) ${ }^{10,11}$ tem sido uma avaliação da aptidão aeróbia, não invasiva e de baixo custo, usada não apenas na prescrição do treinamento, mas também na previsão do desempenho nos domínios pesado e severo de intensidade do exercício ${ }^{10,11,12}$. Isto é, em zonas de intensidade do exercício (entre o limiar de lactato e a VC, ou acima de VC, que delimitam os domínios pesado e severo, respectivamente) em que a tolerância ao esforço não depende (domínio pesado), ou depende (domínio severo), de uma cascata de eventos metabólicos relacionados à perturbação da homeostase muscular e sanguínea ${ }^{11}$. O outro parâmetro, CNA, é o equivalente da capacidade de esforço sustentada pelos metabolismos independentes do oxigênio, indicando a capacidade energética e a tolerância para atividades de intensidade muito alta e curta duração ${ }^{12}$. Na natação, este parâmetro representa a distância que a reserva anaeróbia permitiria nadar antes da exaustão ${ }^{10}$.

Especula-se que a composição corporal seja um fator influente sobre a aptidão aeróbia e produção de força, uma vez que as relações da massa magra (MM) com o consumo de oxigênio $\left(\mathrm{VO}_{2}\right)$ e com a capacidade de força caracterizam as especificidades funcionais de atle- tas e não-atletas ${ }^{13}$. No entanto, a influência da composição regional e corporal total sobre a aptidão aeróbia e neuromuscular dos nadadores ainda pode ser esclarecida. Sabe-se que a composição corporal total é importante no processo de treinamento, pois permite otimizar o desempenho desportivo e monitorar as adaptações corporais ${ }^{14,15}$. Além disto, intuitivamente, técnicos de natação procuram diminuir a gordura corporal total e aumentar a massa muscular, como estratégia para melhorar o desempenho de nado, entretanto, não há evidências científicas que sustentam essa suposição ${ }^{14}$. Provavelmente, a influência da hidrodinâmica corporal sobre o desempenho, bem como a influência de uma elevada capacidade metabólica (oxidativa e/ou gicolítica) e da economia de nado tendem a ser os principais determinantes do desempenho de longa e/ou curta duração ${ }^{15}$. Mas, alguns autores sugerem que a capacidade de desempenho de curta duração possa estar associada a uma maior massa magra e menor gordura corporal ${ }^{16}$. Essa afirmação é respaldada pela tendência de uma maior massa tecidual metabolicamente ativa em sustentar maior nível de força, assim como, uma maior contribuição energética ${ }^{17,18}$.

Porém, estudos que analisaram a influência do treinamento de força ${ }^{17,18}$, ou da melhora da aptidão aeróbia ${ }^{19,20}$, sobre o desempenho de nado de curtas ou longas distâncias, não relataram a influência da composição corporal total associadas às alterações mecânicas e metabólicas. Tampouco existem estudos que analisaram a contribuição da composição regional de nadadores para o perfil da aptidão aeróbia/anaeróbia e força da braçada. Assim, o presente estudo teve por objetivo analisar a influência da composição regional e corporal total sobre índices mecânicos e fisiológicos da aptidão aeróbia e anaeróbia do nadador, em nado-atado e livre, bem como sobre os desempenhos que demanda elevada taxa oxidativa (200 e 400 metros) e endurance aeróbia (800 metros) ${ }^{3,21}$. Especula-se que a quantidade de massa magra regional e corporal total tende a influenciar os desempenhos dependentes da aplicação de uma elevada taxa metabólica e força.

\section{MATERIAIS E MÉTODOS}

Onze nadadores $(18,0 \pm$ 4,0 anos, 180,2 $\pm 6,8 \mathrm{~cm} ; 71,8 \pm 9,5 \mathrm{~kg}$, todos homens) foram submetidos aos protocolos de (1) força-atada máxima; (2) incremental máximo; e (3) tempo-limite em distâncias fixas. Os nadadores apresentavam experiência de, ao menos, três anos de treinamento regular. No momento das avaliações, o volume semanal de treinamento era $25 \mathrm{~km}$. Os nadadores também foram avaliados quanto à composição regional e corporal total. Todos preencheram e assinaram um termo de consentimento livre e esclarecido. Esta pesquisa foi aprovada pelo Comitê de Ética da Universidade (CAEE: 02402512.7.0000.5398). 


\section{Delineamento Experimental}

Os nadadores completaram quatro etapas de avaliações, com intervalo de 24 horas cada. Na primeira etapa, foram avaliadas a composição regional e corporal total e a força máxima pico e média em nado-atado $\left(F_{\text {maxAtada }}\right.$ e $\left.F_{\text {medAtada }}\right)$. Na segunda etapa, aplicou-se um teste incremental. Na terceira e quarta etapas, os nadadores realizaram três desempenhos nas distâncias de 200, 400 e 800 metros para determinar a velocidade crítica (VC) e a capacidade de nado anaeróbia (CNA). Os testes foram realizados em piscina coberta de $25 \mathrm{~m}$, com água à $27^{\circ} \mathrm{C}$. As avaliações foram realizadas durante o período preparatório básico da periodização. Um período de familiarização ao nado-atado foi realizado previamente aos testes. Os nadadores também foram instruídos a não treinar exaustivamente, não ingerir bebidas contendo cafeína e álcool nas 24 horas que antecederam os testes e comparecer alimentados e hidratados.

O método de absociometria por raio-X de dupla energia (DEXA, Hologic ${ }^{\circledR}$, QDR Discovery Wi ${ }^{\circledR}$ Bedford, EUA) foi utilizado para obter a composição regional e corporal total. Os valores de massa gorda (MG), massa total (MT) e massa isenta de gordura (massa magra e conteúdo mineral ósseo, MIG), foram obtidos para as regiões corporais (pernas e braços do lado direito e esquerdo do corpo, tronco e cabeça) e para o corpo todo. As composições de MG, MT e MIG do membro superior (MS) e inferior (MI) foram obtidas pela soma dos respectivos pares de parâmetros de cada região. O peso corporal total (PC) foi considerado o resultado da soma de todas as MT regionais.

O equipamento foi calibrado conforme recomendações do fabricante e todo procedimento foi operado por um técnico experiente. Os procedimentos de avaliação seguiram as sugestões de Nana et al. 22. (a) os participantes apresentaram-se com roupas leves, sem sapatos e sem portar qualquer objeto metálico, ou acessórios junto ao corpo; e (b) permaneceram deitados em decúbito dorsal, com 15 centímetros de distância entre os pés, mão em posição de semipronação e a $3 \mathrm{~cm}$ do tronco ao longo da lateral do tronco. $\mathrm{O}$ alinhamento anatômico obedeceu aos pontos específicados pelo programa.

$F_{\text {maxAtada }}$ e $F_{\text {medAtada }}$ foram determinadas com dois esforços máximos de 30 s cada, intervalados por 10 minutos de recuperação, e executados em nado-crawl atado à uma corda inelástica, que estava atrelada ao sistema de medida. Esse sistema consistiu em uma célula de carga de 500 kgf, previamente calibrada. Os dados foram filtrados e suavizados pelo programa de análise do fabricante (N2000PRO, Cefise ${ }^{\circledR}$, Campinas, São Paulo, Brasil). A $F_{\text {maxAtada }}$ foi representada em $\mathrm{N}$, considerando a média dos picos de força nos 5 segundos iniciais; e a $F_{\text {medAtada }}$ foi considerada a média dos picos de todo o intervalo de coleta 8 .

Os sujeitos desempenharam um teste incremental contínuo, com intensidade da carga variando em $5 \%$, na faixa entre $30-100 \%$ da $\mathrm{F}_{\text {medAtada }}$ em intervalos de um minuto, conforme proposto por Siqueira et al. ${ }^{23}$. Durante os testes, a permuta gasosa pulmonar foi coletada respiração-a-respiração, empregando um sistema automatizado portátil (K4b2 ${ }^{2}$ Cosmed, Roma, Itália), conectado ao nadador por um tubo (snorkel) respiratório especial e sistema de válvula tridimensional (novo-Aquatrainer ${ }^{\circledR}$, Cosmed, Roma, Itália), validado por Baldari et al. ${ }^{24}$. A calibração do sistema foi realizada de acordo com as instruções do fabricante.

O maior valor do $\mathrm{VO}_{2}$, após suavização (filtro de $3 \mathrm{~s}$ ) e ponderação (média em intervalos de 9s), foi considerado o $\mathrm{VO}_{2 \text { max }}$ O limiar de permuta gasosa ( $L P G)$ e ponto de compensação respiratória (PCR), foram determinados conforme as recomendações de Beaver et al. ${ }^{25}$. Os critérios para determinar o LPG foram: aumento na curva da relação $V_{E} / N_{2}$ e na $P_{E T} O_{2}$, sem alteração da relação $V_{E} / N_{C O}$ e na $\mathrm{P}_{\mathrm{ET}} \mathrm{CO}_{2}$. Para $\mathrm{PCR}$ : aumento concomitante e sustentado dos parâmetros $\mathrm{V}_{\mathrm{E}} \mathrm{NO}_{2}$ e $\mathrm{V}_{\mathrm{E}} / \mathrm{NCO}_{2}$, concomitante à diminuição da $\mathrm{P}_{\mathrm{ET}} \mathrm{CO}_{2}$. Os pontos de localização de LPG e PCR foram detectados por dois observadores independentes. $\mathrm{A} \mathrm{iVO}_{2 \max }$ foi considerada como sendo a menor carga durante o teste incremental atado na qual ocorreu o $\mathrm{VO}_{2 \max }{ }^{26}$. O mesmo critério foi adotado para determinar iLPG e iPCR. A carga correspondente ao maior estágio do protocolo foi considerada a intensidade máxima incremental (iMax).

Em condições de nado-atado progressivo, o teste foi considerado máximo se atendeu ao menos dois entre os critérios de esforço máximo: quociente respiratório $(\mathrm{QR}) \geq 1,1$; frequência cardíaca $(\mathrm{FC}) \geq$ $90 \% \mathrm{FC}_{\max }(=207-0,7 \times \text { idade })^{27}$; e concentração sanguínea de lactato $\geq 8\left(\mathrm{mmol} . \mathrm{I}^{-1}\right)^{28}$. A coleta de sangue foi realizada imediatamente após o teste, para a dosagem da concentração do lactato (YSL, 2300 STAT Plus, Yellow Springs, EUA). A FC foi registrada usando um frequencímetro (POLAR ${ }^{\circledR}$, Kempele, Finland) acoplado e sincronizado ao sistema de análise dos parâmetros respiratórios.

A velocidade crítica (VC) e magnitude da reserva anaeróbia em metros (CNA) foram determinadas, respectivamente, pela inclinação e intercepto da relação linear entre distância e tempo (modelo $d$ - $t_{\text {Lim }}$ ), a partir dos desempenhos nas distâncias de 200, 400 e 800 m ( $t_{200 m}$, $t_{400 m}$, e $t_{800 m}$ ), conforme procedimentos descritos por Dekerle et al.. ${ }^{10}$.

\section{Análise estatística}

Os dados obtidos foram analisados quanto à normalidade pelo teste de Shapiro-Wilk. As regressões lineares do modelo $d$ - $t_{\text {Lim }}$ empregaram o método dos quadrados mínimos. O coeficiente de Pearson ( $r$ ) correlacionou à composição regional e corporal total com índices de aptidão aeróbia e anaeróbia em nado-atado e livre. Todas as análises foram realizadas no PASW 18.0 (SPSS Inc. Chicago, EUA). Adotou-se nível de significância em $\rho \leq 0,05$.

\section{RESULTADOS}

Os valores da composição regional e corporal total são apresentados na Tabela 1. A F medAtada no nado crawl-atado em máxima intensidade foi equivalente à 2,9 $\pm 0,6{\mathrm{~N} \times \mathrm{kg}^{-1}}^{-1}$, cujas frações submáximas gerenciaram a progressão dos níveis de intensidade durante o teste, conduzindo os nadadores ao esforço máximo no estágio final (QR: 1,1 $\pm 0,1$; FC: 92,9 \pm 4,2\%FCmax; e lactato: 7,3 $\left.\pm 1,4 \mathrm{mmolxl}^{-1}\right)$. Assim, foi possível identificar o $\mathrm{VO}_{2 \max }$ em 3720,4 \pm 426,4 ${\mathrm{ml} \times \mathrm{min}^{-1}}^{-1}(52,1 \pm 5,3$ $\left.\mathrm{ml} \times \mathrm{kg}^{-1} \times \mathrm{min}^{-1}\right)$ e a intensidade de carga correspondente $\left(\mathrm{iVO}_{2 \max }\right) \mathrm{em}$ $93,9 \pm 12,2 \mathrm{~N}$. Bem como, localizou-se LPG e PCR em termos relativos ao $\mathrm{VO}_{2 \max }\left(67,9 \pm 7,4 \%\right.$ e $87,7 \pm 3,6 \%$, respectivamente) e à iVO ${ }_{2 \max }$ $(62,7 \pm 4,3 \%$ e $85,2 \pm 2,9 \%$, respectivamente).

As distâncias de 200 ( $\left.\mathrm{t}_{200 \mathrm{~m}}: 132,2 \pm 9,7 \mathrm{~s}\right), 400 \mathrm{~m}(296,8 \pm 17,2 \mathrm{~s}$ ) e $800 \mathrm{~m}(619,5 \pm 26,9 \mathrm{~s})$, forneceram valores de VC e CNA de 1,23 \pm $0,06{\mathrm{~m} \times \mathrm{s}^{-1}}^{-1}$ e 35,8 $\pm 15,1 \mathrm{~m}$, respectivamente. As velocidades em cada

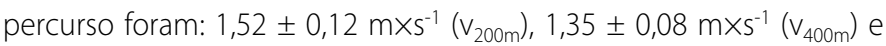
$1,29 \pm 0,05{\mathrm{~m} \times \mathrm{s}^{-1}}^{-1}\left(\mathrm{v}_{800 \mathrm{~m}}\right)$. A Figura 1 exemplifica o procedimento adotado na determinação de VC e CNA.

As correlações da composição regional e corporal total revelam que os parâmetros MIG e MG (regional e corporal total) apresentaram correlações significativas com os parâmetros do esforço de alta intensidade (iMax, iVO $\mathrm{VO}_{2}$ iPCR, CNA e $\mathrm{V}_{200 \mathrm{~m}}$, Tabelas 2 e 3). Por outro lado, a magnitude da taxa oxidativa correspondente ao $\mathrm{VO}_{2 \max }\left(\mathrm{ml} \times \mathrm{kg}^{-1} \times \mathrm{min}^{-1}\right)$

Tabela 1. Valores da composição regional e corporal total.

\begin{tabular}{c|c|c|c}
\hline Parâmetros/Regiões & MIG $(\mathbf{k g})$ & $\mathbf{M T}(\mathbf{k g})$ & $\% \mathbf{G}$ \\
\hline Corporal Total & $61,7 \pm 7,4$ & $71,8 \pm 9,1$ & $13,8 \pm 5,0$ \\
\hline Membro Superior & $7,5 \pm 1,1$ & $8,5 \pm 1,2$ & $11,7 \pm 5,3$ \\
\hline Tronco & $28,3 \pm 3,7$ & $32,3 \pm 4,6$ & $12,2 \pm 5,4$ \\
\hline Membro Inferior & $22,1 \pm 2,5$ & $26,3 \pm 3,4$ & $15,6 \pm 5,6$ \\
\hline Obs:."MIG,MTe\%G"correspondem à massa isenta de gordura, massa total e percentual de gordura, respectivamente.
\end{tabular}


e à PCR ( $\left.\mathrm{ml} \times \mathrm{kg}^{-1} \times \mathrm{min}^{-1}\right)$ correlacionou-se apenas com a MT de MS (0,67 e 0,62; $p=0,02$ e 0,04, respectivamente), sendo as MT de tronco e MI influentes também sobre o $\mathrm{VO}_{2 \max }\left(\mathrm{ml} \times \mathrm{kg}^{-1} \times \mathrm{min}^{-1}\right): 0,60(p=0,05)$ e $0,63(p=0,04)$, respectivamente.

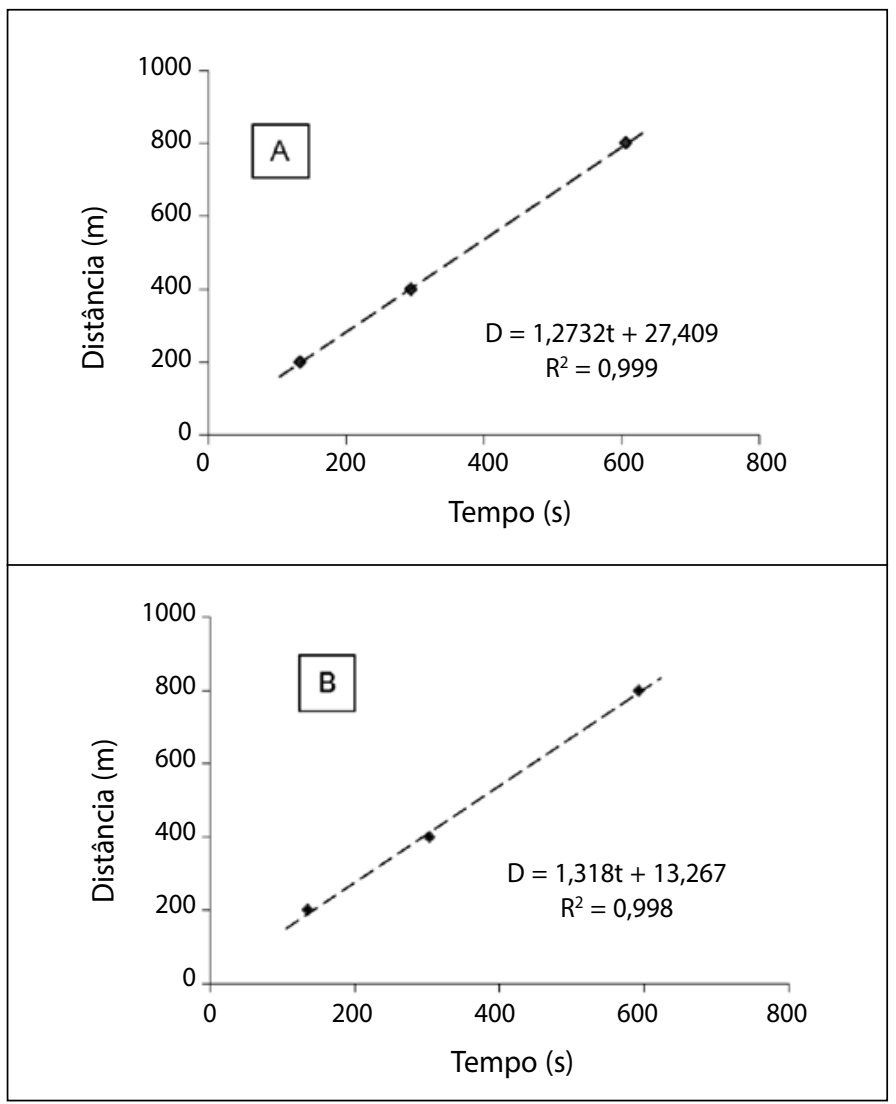

Figura 1. Determinação de VC e CNA de ajuste linear. O gráfico A e B representam os sujeitos 1 e 5 , respectivamente.

Tabela 2. Correlações da massa isenta de gordura (MIG) regional e corporal total sobre a aptidão aeróbia e anaeróbia, e desempenho em nado livre e atado.

\begin{tabular}{c|c|c|c|c}
\hline $\begin{array}{c}\text { Parâmetros/ } \\
\text { Índices }\end{array}$ & MIG-MS & MIG-T & MIG-MI & MIG $_{\text {Total }}$ \\
\hline iMax $(\mathrm{kg})$ & $\begin{array}{c}0,62^{*} \\
(p=0,040)\end{array}$ & $\begin{array}{c}0,57 \\
(p=0,069)\end{array}$ & $\begin{array}{c}0,60^{*} \\
(p=0,050)\end{array}$ & $\begin{array}{c}0,60^{*} \\
(p=0,050)\end{array}$ \\
\hline $\mathrm{iVO}_{2 \max }(\mathrm{kg})$ & $\begin{array}{c}0,64^{*} \\
(p=0,034)\end{array}$ & $\begin{array}{c}0,55 \\
(p=0,079)\end{array}$ & $\begin{array}{c}0,56 \\
(p=0,073)\end{array}$ & $\begin{array}{c}0,58 \\
(p=0,062)\end{array}$ \\
\hline $\mathrm{iPCR}(\mathrm{kg})$ & $\begin{array}{c}0,61^{*} \\
(p=0,045)\end{array}$ & $\begin{array}{c}0,54 \\
(p=0,089)\end{array}$ & $\begin{array}{c}0,53 \\
(p=0,091)\end{array}$ & $\begin{array}{c}0,56 \\
(p=0,076)\end{array}$ \\
\hline $\mathrm{V}_{200 m}\left(\mathrm{~m} \times s^{-1}\right)$ & $\begin{array}{c}0,76^{* *} \\
(p=0,006)\end{array}$ & $\begin{array}{c}0,75^{* *} \\
(p=0,007)\end{array}$ & $\begin{array}{c}0,69^{*} \\
(p=0,020)\end{array}$ & $\begin{array}{c}0,74^{* *} \\
(p=0,008)\end{array}$ \\
\hline $\mathrm{CNA}(\mathrm{m})$ & $\begin{array}{c}0,67^{*} \\
(p=0,025)\end{array}$ & $\begin{array}{c}0,71^{*} \\
(p=0,014)\end{array}$ & $\begin{array}{c}0,69^{*} \\
(p=0,020)\end{array}$ & $\begin{array}{c}0,71^{*} \\
(p=0,014)\end{array}$ \\
\hline
\end{tabular}

$\left.{ }^{*}\right)$ Significativo à $r £ 0,05$. (**) Significativo à $r £ 0,01$. "MIG-MS, MIG-T, MIG-MS, MIG-Ml e MIG Gota" correspondem à massa isenta de gordura para os braços, tronco, pernas e corporal total , respectivamente.

Tabela 3. Correlações da massa gorda (MG) regional e corporal total sobre parâmetros do desempenho aeróbio em nado-atado.

\begin{tabular}{c|c|c|c|c}
\hline $\begin{array}{c}\text { Parâmetros/ } \\
\text { Índices }\end{array}$ & MG-MS & MG-T & MG-MI & $\mathbf{M G}_{\text {Total }}$ \\
\hline$i M a x\left(N \times \mathrm{kg}^{-1}\right)$ & $\begin{array}{c}-0,66^{*} \\
(p=0,028)\end{array}$ & $\begin{array}{c}-0,73^{*} \\
(p=0,011)\end{array}$ & $\begin{array}{c}-0,67^{*} \\
(p=0,023)\end{array}$ & $\begin{array}{c}-0,72^{*} \\
(p=0,012)\end{array}$ \\
\hline$i \mathrm{VO}_{2 \max }\left(\mathrm{N} \times \mathrm{kg}^{-1}\right)$ & $\begin{array}{c}-0,53 \\
(p=0,095)\end{array}$ & $\begin{array}{c}-0,66^{*} \\
(p=0,028)\end{array}$ & $\begin{array}{c}-0,60^{*} \\
(p=0,050)\end{array}$ & $\begin{array}{c}-0,64^{*} \\
(p=0,034)\end{array}$ \\
\hline $\mathrm{i} L \mathrm{PG}\left(\mathrm{N} \times \mathrm{kg}^{-1}\right)$ & $\begin{array}{c}-0,53 \\
(p=0,091)\end{array}$ & $\begin{array}{c}-0,67^{*} \\
(p=0,024)\end{array}$ & $\begin{array}{c}-0,64^{*} \\
(p=0,032)\end{array}$ & $\begin{array}{c}-0,67^{*} \\
(p=0,025)\end{array}$ \\
\hline
\end{tabular}

(*) Significativo à r $£ 0,05$."MG" corresponde à massa de gordura para o MS, T, Ml, e corporal total, respectivamente.

\section{DISCUSSÃO}

A presente hipótese considerou a composição regional e corporal total como possíveis fatores influentes no desempenho de alta intensidade e duração moderada a curta. Nestas condições, o desempenho de nado depende da aplicação e sustentação da força de braçada e, consequentemente, da capacidade metabólica muscular em ativar e, continuadamente, ajustar a ressíntese oxidativa de ATP em elevada taxa ${ }^{3,20,21}$. Os resultados apresentados destacam a massa isenta de gordura na região dos membros superiores (MIG-MS) como um fator influente no desempenho de nado em intensidade correspondente à taxa oxidativa máxima $\left(\mathrm{iVO}_{2 \mathrm{max}}\right)$, à velocidade máxima de progressão em teste incremental (iMax), ao limite superior do exercício sem fadiga metabólica (iPCR), à magnitude das reservas anaeróbias de energia (CNA) e, consequentemente, à velocidade de desempenho nos 200 metros $\left(V_{200 m}\right)$. Ao considerar que a massa isenta de gordura na região do tronco (MIG-T), membros inferiores (MIG-MI) e no corpo ( $\mathrm{MIG}_{\text {Total }}$ ) também demonstraram influência sobre CNA e $v_{200 m}$, pôde-se inferir que há uma tendência da quantidade de MIG regional e corporal total em influenciar positivamente os desempenhos que apresentam características metabólicas do exercício de alta intensidade e curta duração. Assim, a MIG tende a afetar não apenas a intensidade de nado, mas também a tolerância de esforço em perfis metabólicos caracterizados por uma alta taxa de ativação oxidativa e lenta, porém progressiva, demanda sobre as reservas anaeróbias ${ }^{11,12}$.

A relação positiva entre $M I G-M S$ e a $\mathrm{iVO}_{2 \text { max }}$ bem como com iPCR e iMax, pressupõe, portanto, que uma maior massa isenta de gordura tende a proporcionar maior velocidade em distâncias em que a tolerância ao exercício de alta-intensidade é um elemento decisivo. Na natação, essas distâncias envolvem os 200, 400 e 800 metros $^{21}$. Mas, a economia de nado é outro fator importante na tolerância ao esforço nestas distâncias ${ }^{3,6,21}$. A economia tem-se atribuído o papel de redução da demanda energética submáxima ${ }^{20}$ e preservação das reservas anaeróbias ${ }^{21,26}$, assim, alterando a velocidade de desempenho correspondente à um evento metabólico determinante $\left(\mathrm{VO}_{2 \max } \text { e PCR }\right)^{20}$ e o tempo-limite do exercício (tolerância) em alta-intensidade ${ }^{6,26}$, ao evitar uma demanda precoce sobre as reservas anaeróbias ${ }^{11,21,26}$. Apesar da economia de nado e tempo-limite em índices fisiológicos não terem sido temáticas abordadas no presente estudo, pode-se sugerir, ao menos hipoteticamente, a existência de uma relação destes parâmetros com a MIG. Isso porque a massa muscular contribui significativamente para a massa isenta de gordura ${ }^{22}$, cujos métodos de desenvolvimento envolvem o treinamento em alta intensidade dentro e fora do meio-líquido, promovendo aprimoramento da capacidade de aplicar e sustentar a força ${ }^{17,18}$, bem como o refinamento no padrão de ativação e recrutamento das unidades motoras ${ }^{2}$. Esses pressupostos auxiliam na explicação da influência da MIG-MS sobre iVO $\mathrm{Imax}_{\text {max }}$ e iPCR e não sobre as taxas metabólicas correspondentes.

Outros estudos têm observado a influência da composição corporal total sobre o desempenho de nado. Em pré-adolescentes ( 9 a 10 anos), a massa magra corpórea (avaliada pelo método de dobras cutâneas) não se mostrou relacionada ao desempenho do nado peito, mas a gordura corporal e dobras cutâneas da porção superior do corpo revelaram-se negativamente relacionadas ${ }^{29}$. No entanto, esses autores mostraram haver uma relação positiva entre o componente mesomórfico e o desempenho do peito em testes de curta distância, salientando que esta característica corpórea retrata a capacidade dos músculos em gerar força e, possivelmente, a utilização desta força na melhora da distância percorrida por ciclo de braçada. No presente estudo, o perfil regional e corporal total de massa gorda, que refletiria a tendência à endomorfia ${ }^{16}$, apresentou influência negativa com o desempenho associado tanto a uma demanda oxidativa elevada $\left(\mathrm{iVO}_{2 \max }\right.$ ) como moderada (iLPG), corroborando os resultados de Rad 
e Mohammadi ${ }^{29}$ e Siders et al. ${ }^{16}$. Porém, acrescenta-se que a gordura corporal total, ou em regiões pouca ativas em relação ao movimento dos braços (como o tronco e MI), tendem a prejudicar o perfil aeróbio entre nadadores. Mesmo alguns relatos contextualizando a importância da gordura corporal na hidrodinâmica corporal, pela influência sobre a flutuabilidade ${ }^{5,14}$, o presente estudo denota que seu excesso pode comprometer o desempenho de longa e de moderada à curta duração, pela associação negativa com iLPG e iVO $\mathrm{Imax}$

Deve-se também ressaltar a importância metabólica da massa isenta de gordura regional e corporal total. Ogita et al. ${ }^{30}$ destacaram que a quantidade de massa muscular ativa nos membros durante os movimentos das pernas e braços, tende a ser mais contundente em esforços de curta duração e alta intensidade (2 a 3 minutos de duração), ao considerar a capacidade de ressíntese energética (aeróbia e anaeróbia). No entanto, a quantidade de massa muscular envolvida nas ações isoladas de braços e pernas (regional) durante o nado foi um determinante da capacidade anaeróbia avaliada pelo máximo déficit de $\mathrm{O}_{2}$ acumulado. Para esses autores, esse fato demonstra um ajuste compensatório à limitação central à oferta de $\mathrm{O}_{2}$ durante o exercício de alta intensidade realizado por nadadores com grande massa muscular regional, especialmente nos braços. A relação positiva apresentada entre massa magra regional e a reserva anaeróbia (CNA) (Tabela 2), no presente estudo, corrobora essa interdependência.

Embora a massa total (MT) regional e corporal total tenha apresentado influência positiva sobre a taxa absoluta máxima de ativação do sistema oxidativo $\left(\mathrm{VO}_{2 \mathrm{max}}\right)$, não foram observadas relações destas massas e do $\mathrm{VO}_{2 \max } \mathrm{com}$ o desempenho de nado. A compreensão desta ausência influência (MT regional e corporal total vs. $\mathrm{VO}_{2 \max }$ Vs. desempenho de nado) é dada pelas observações sobre a pouca influência das características de tamanho corporal e potencial oxidativo sobre o desempenho de nado $3,5,15$, ao confrontar com outros parâmetros, como o nível de habilidade ${ }^{21}$, a maturidade corporal ${ }^{16} \mathrm{e}$ o nível de treinamento ${ }^{18}$. O presente estudo acrescenta a essa lista a capacidade oxidativa em LPG e PCR, que não se mostraram relacionadas aos parâmetros da composição regional e corporal total, ou ao desempenho. Em outras palavras, um maior tecido metabolicamente ativo não significa maior capacidade de resposta oxidativa ao incremento de carga, mas talvez uma tendência em reduzir a demanda de $\mathrm{O}_{2}$ por unidade de carga durante a progressão da intensidade.

\section{CONCLUSÃO}

Os resultados revelaram uma associação entre a MIG (regional e corporal total) com a força da braçada e a velocidade de nado em curtas distâncias. Portanto, pode-se concluir, mesmo não incluindo a avaliação do desempenho nos 50 e 100 metros, que o desenvolvimento da MIG, principalmente nos membros superiores, deve integrar o plano de treinamento, quando à especificidade seja o desempenho em eventos que demandam elevada taxa de ativação dos metabolismos oxidativo e glicolítico.

\section{AGRADECIMENTOS}

Os autores agradecem ao CNPQ pelo apoio financeiro dado a este trabalho.

Todos os autores declararam não haver qualquer potencial conflito de interesses referente a este artigo.

CONTRIBUIÇÕES DOS AUTORES: Cada autor contribuiu individual e significativamente para o desenvolvimento do manuscrito. DMPF (0000-0003-3975-9260)*, ARS $(0000-0003-0653-5383)^{*}$ e LOCS (0000-0003-0585-4593)* foram responsáveis pela idealização da proposta, coleta de dados, apresentação dos resultados e discussão literária dos resultados observados. MACE (0000-0002-4524-4784)*, acompanhou o tratamento dos dados e contribuiu para a revisão do manuscrito e construção da base conceitual do estudo. DP (0000-0003-3832-9904)*, participou do processo de coleta dos dados, armazenamento e tratamento do dados, bem como da revisão conceitual final. *Número ORCID (Open Researcher and Contributor ID).

\section{REFERÊNCIAS}

1. Yeater RA, Martin RB, White MK, Gilson KH. Tethered swimming forces in the crawl, breast and back strokes and their relationship to competitive performance. J Biomech. 1981;14(8):527-37.

2. Cabri JMH, Annemans $L$, Clarys JP. The relation of stroke frequency, force, and EMG in font crawl tethered swimming. In: Ungerechts BE, Wilke K, Reischle K, editors. Biomechanics and medicine in swimming Champaign, IL: Human Kinetics; 1988. p. 183-9.

3. Pyne DB, Sharp RL. Physical and energy requirements of competitive swimming events. Int J Sport Nutr Exerc Metab. 2014;24(4):351-9

4. Papoti M, Vitório R, Araújo GS, Martins LEB, Cunha AS, Gobatto CA. Força crítica em nado atado para avaliação da capacidade aeróbia e predição de performances em nado livre. Rev Bras Cineantropom Desempenho Hum. 2010;12(1):14-20.

5. Clarys JP. Human morphology and hydrodynamics. In: Terauds J, Bedingfield EW. editors. Swimming III. Baltimore: University Park Press; 1979. p.3-41.

6. Fernandes RJ, Keskinen KL, Colaço P, Querido AJ, Machado LJ, Morais PA, et al. Time limit at VO2max velocity in elite crawl swimmers. Int J Sports Med. 2008;29(2):145-50.

7. Pinna M, Milia R, Roberto S, Marongiu E, Olla S, Loi A, Ortu M, et al. Assessment of the specificity of cardiopulmonary response during tethered swimming using a new snorkel device. J Physiol Sci. 2013;63(1):7-16.

8. Morouço P, Keskinen KL, Vilas-Boas JP, Fernandes RJ. Relationship between tethered forces and the four swimming techniques performance. J Appl Biomech. 2011;27(2):161-9.

9. Pessôa Filho DM, Greco CC, Denadai SB. Tether-power at maximal lactate steady-state and endurance indexes of swimming performance. Rev Bras Med Esporte. 2014;20(5):359-65.

10. Dekerle J, Brickley G, Alberty M, Pelayo P. Characterinzing the slope of the distance-time relationship in swimming. J Sci Med Sports. 2010;13(3):365-70

11. Murgatroyd SR, Ferguson C, Ward SA, Whipp BJ, Rossiter HB. Pulmonary $\mathrm{O}_{2}$ uptake kinetics as a determinant of high-intensity exercise tolerance in humans. J Appl Physiol. 2011;110(6):1598-606.

12. Jones AM, Vanhatalo A, Burnley M, Morton RH, Poole DC. Critical power: implications for determination of $\mathrm{VO}_{2 \max }$ and exercise tolerance. Med Sci Sports Exerc. 2010,42(10):1876-90.13

13. Santos DA, Dawson JA, Matias CN, Rocha PM, Minderico CS, Allison DB, et al. Reference values for body composition and anthropometric measurements in athletes. PLoS One. 2014;9(5):e97846.

14. Lowensteyn I, Signorile JF, Giltz K. The effect of varying body composition on swimming performance. J Strength Cond Res. 1994;8(3):149-54

15. Lätt E, Jürimäe J, Mäestu J, Purge P, Rämson R, Haljaste K, et al. Physiological, biomechanical and anthropometrical predictors of sprint swimming performance in adolescent swimmers. J Sports Sci Med. 2010;9(3):398-404.
16. Siders WA, Lukaski HC, BolonchukWW. Relationships among swimming performance, body composition and somatotype in competitive collegiate swimmers. J Sports Med Phys Fitness. 1993;33(2):166-71.

17. Girold S, Maurin D, Dugué B, Chatard JC, Millet G. Effects of dry-land vs. resisted- and assisted-sprint exercises on swimming sprint performances. J Strength Cond Res. 2007;21(2):599-605.

18. Toussaint $\mathrm{HM}$, Vervoorn $\mathrm{K}$. Effects of specific high resistance training in the water on competitive swimmers. Int J Sports Med. 1990;11(3):228-33.

19. Jorgić B, Puletić M, Okičić T, Meškovska N. Importance of maximal oxygen consumption during swimming. Facta Universitatis Ser Physl Educ Sport. 2011;9(2):183-91.

20. Wakayoshi K, D'Acquisto LJ, Cappaert JM, Troup JP. Relationship between oxygen uptake, stroke rate and swimming velocity in competitive swimming. Int J Sports Med. 1995;16(1):19-23.

21. Toussaint HM, Hollander AP. Energetics of competitive swimming. Implications for training programmes Sports Med. 1994;18(6):384-405

22. Nana A, Slater GJ, Hopkins WG, Burke LM. Techniques for undertaking dual-energy X-ray absorptiometry whole-body scans to estimate body composition in tall and/or broad subjects. Int I Sport Nutr Exerc Metab. 2012;22(5):313-22.

23. Siqueira LOC, Simionato AR, Pestana D, Barreto NA, Espada MAC, Pessôa Filho DM. Tendência de ajuste da relação $\mathrm{VO}_{2}$ versus intensidade de nado-atado. Motriz 2015;21(02):S54-5.

24. Baldari C, Fernandes RJ, Meucci M, Ribeiro J, Vilas-Boas JP, Guidetti L. Is the new AquaTrainer ${ }^{\bullet}$ snorke valid for VO2 assessment in swimming? Int J Sports Med. 2013;34(4):336-44

25. Beaver WL, Wasserman K, Whipp BJ. A new method for detecting anaerobic threshold by gas exchange J Appl Physiol (1985). 1986;60(6):2020-7

26. Billat V, Faina M, Sardella F, Marini C, Fanton F, Lupo S, et al. A. comparison of time to exhaustion at $\mathrm{VO}_{2 \max }$ in elite cyclist, kayak paddlers, swimmers and runners. Ergonomics. 1996;39(2):267-77.

27. Tanaka H, Monahan KD, Seals DR. Age-predicted maximal heart rate revisited. J Am Coll Cardiol 2001;37(1):153-6.

28. Poole DC, Wilkerson DP, Jones AM. Validity of criteria for establishing maximal $\mathrm{O} 2$ uptake during ramp exercise tests. Eur J Appl Physiol. 2008;102(4):403-10

29. Rad LS, Mohammadi V. The relationship between anthropometric characteristics, somatotype, and breaststroke performance after a 12-session training period. Int J Sport Studies. 2013;3(10):1109-15.

30. Ogita F, Hara M, Tabata I. Anaerobic capacity and maximal oxygen uptake during arm stroke, leg kicking and whole body swimming. Acta Physiol Scand. 1996;157(4):435-41. 